\title{
Perturbed Zinc Homeostasis in Rural 3-5-y-Old Malawian Children Is Associated With Abnormalities in Intestinal Permeability Attributed to Tropical Enteropathy
}

\author{
MICAH J. MANARY, STEVEN A. ABRAMS, IAN J. GRIFFIN, MEGAN M. QUIMPER, ROBERT J. SHULMAN, \\ MARIA G. HAMZO, ZHENSHENG CHEN, KENNETH MALETA, AND MARK J. MANARY
}

\author{
Department of Pediatrics, [M.J.M., M.M.Q., M.J.M.], Washington University School of Medicine, St. Louis, Missouri 63110; Department \\ of Pediatrics, [S.A.A., R.J.S., M.G.H., Z.C., M.J.M.], Baylor College of Medicine, Houston, Texas 77030; Department of Pediatrics, \\ [I.J.G.], University of California Davis, Davis, California 95616; Department of Community Health, [K.M., M.J.M.], University of Malawi \\ College of Medicine, Blantyre 3, Malawi
}

\begin{abstract}
Tropical enteropathy and zinc deficiency are major public health problems worldwide. Tropical enteropathy is characterized by reduced mannitol absorption with normal or increased lactulose absorption when a dual sugar absorption test is administered, the results of which are reported as the lactulose:mannitol ratio (L:M). Zinc homeostasis is quantified with a dual stable isotope test. This study tested the hypothesis that endogenous fecal zinc (EFZ) was correlated with the L:M. A dual sugar absorption test and dual stable isotope test were performed on 25 asymptomatic Malawian children aged 3-5 y at risk for tropical enteropathy and zinc deficiency. EFZ and net zinc retention were estimated and correlated with the L:M. Twenty-two children (88\%) had an abnormal L:M (L:M >0.10), and the L:M was $0.24 \pm 0.10$ (mean $\pm \mathrm{SD}$ ). EFZ was $1.68 \pm 1.06 \mathrm{mg} / \mathrm{d}$, a quantity greater than is seen in healthy populations from the developed world. EFZ was positively correlated with the L:M $(r=0.62, p<0.001)$. Net zinc retention $(0.67 \pm 1.6 \mathrm{mg} / \mathrm{d})$ was negatively correlated with the L:M ( $r=-0.47, p=0.02)$. This suggests that perturbed zinc homeostasis is associated with subclinical enteropathy in these children. (Pediatr Res 67: 671-675, 2010)
\end{abstract}

$\mathrm{Z}$ inc deficiency is estimated to account for $4.4 \%$ of child deaths worldwide, and one-third of the world's children are at risk for zinc deficiency (1). The morbidity associated with zinc deficiency includes stunting, reduced capacity for physical work, and increased susceptibility to infection. Zinc retention in humans is not simply determined by the amount of dietary zinc consumed but also by reabsorption of endogenous zinc secreted into the small intestine. The reabsorption of endogenous zinc from the gut is believed to be a mechanism by which zinc homeostasis is maintained (2). The dual zinc stable isotope test involves administration of different zinc stable isotopes orally and i.v. and has been used to quantify the primary parameters that determine zinc homeostasis (3). Measurements of total dietary absorbed zinc (TAZ), endogenous fecal zinc (EFZ), and net zinc retention (NZR) have been made using this technique (3-6).

Received August 24, 2009; accepted January 11, 2010.

Supported by Cooperative Agreement 58-6250-6001 from the US Department of Agriculture Agricultural Research Service and the International Atomic Energy Agency Contract 14586.

Correspondence: Mark J. Manary, M.D., Department of Pediatrics, St. Louis Children's Hospital, One Children's Place, St Louis, MO 63110; e-mail: manary@kids. wustl.edu
Tropical enteropathy is a diffuse villous atrophy of the small bowel associated with inflammatory $\mathrm{T}$ cell infiltration $(7,8)$. Tropical enteropathy is a chronic, subclinical condition of unknown etiology, distinguished from acute enteropathies associated with gastrointestinal infections. Changes in stool pattern or consistency are not apparent in children with tropical enteropathy. Tropical enteropathy is associated with stunting of otherwise healthy preschool aged children in developing countries (9). The damage to the normal intestinal architecture is associated with compromised capacity to absorb macronutrients (10). Tropical enteropathy is ubiquitous throughout the developing world, prevalence estimates in communities often exceed $75 \%$ (11).

The dual sugar absorption test uses the nonmetabolized sugars mannitol and lactulose, which are administered orally and measured in the urine. The urinary lactulose-to-mannitol ratio (L:M) is a measure of gut absorptive capacity and intercellular permeability (12). Abnormal L:Ms are seen in association with histologic gut inflammation, reduced nutrient absorptive capacity, and growth faltering $(7,9,10)$. Therefore, the dual sugar absorption test has been a noninvasive, surrogate test used to identify tropical enteropathy (11).

Inappropriately, increased levels of EFZ have been observed in a population of Malawian children with poor zinc status, suggesting that a decreased capacity to limit EFZ contributes to zinc deficiency (13). Because tropical enteropathy is also common in this population, we hypothesized that the L:M was correlated with EFZ.

\section{SUBJECTS AND METHODS}

Subjects. All children aged 3-5 y resident in Masika village in southern Malawi were screened for participation in this study. Masika is an isolated population of subsistence farmers growing corn, legumes, and rice, typical of rural Malawi. Residents live in mud huts with grass roofs, collect water from shallow wells, and travel $>70 \mathrm{~km}$ to reach the nearest paved road.

All caretakers of children aged 3-5 y were informed about this study, asked if they wanted to participate and, if so, requested to give their informed

\footnotetext{
Abbreviations: EFZ, endogenous fecal zinc; FAZ, fractional absorbed zinc; L:M, lactulose-to-mannitol ratio; NZR, net zinc retention; TAZ, total dietary absorbed zinc
} 
consent. Consent was obtained through a series of four meetings with mothers and community leaders. Each caretaker gave consent individually.

Each child had weight and height measured, and caretakers were surveyed about the child's health history, especially previous malnutrition. The frequency of the child's hand washing, the child's use of a pit latrine, the amount of water used in the home each day, and the presence of farm animals sleeping with the child were assessed by questionnaire. Associations between the L:M and these common home hygiene practices are known in Malawi (14). All children with wasting or a history of treatment for malnutrition, in addition to all indicating poor hygiene on $3 / 4$ of the questions, were asked to participate in this study. Children with chronic illness were excluded, and children with acute illness were offered treatment and excluded from this study.

Each caretaker invited to participate in this study signed a consent form with the knowledge that at any time they could withdraw from this study. The College of Medicine Research and Ethics Committee, University of Malawi and the Washington University School of Medicine Human Research Protection Office approved this study. This study was determined to be of minimal risk by both review panels.

Study design. This was an observational study in a subset of children living in a typical Malawian village to test the hypothesis that the L:M is positively associated with EFZ.

The children chosen for participation in this study were chosen such that they would most likely include abnormal L:Ms and thus provide an informative dataset for detecting an association between this surrogate test for tropical enteropathy and zinc homeostasis.

On the first day of participation, the participants completed the dual sugar absorption test. The following day, the group began the dual zinc stable isotope test, which lasted for $6 \mathrm{~d}$ total.

The primary outcome was the degree of association between L:M and EFZ, as determined by the Pearson correlation coefficient. Secondary outcomes were the correlation coefficients between the L:M and TAZ, NZR, and serum zinc concentration.

The sample size was chosen to be 25 children. It was assumed that the variances of the EFZ and the L:M measurements would be similar to that observed in our zinc isotope and tropical enteropathy studies $(13,14)$. A correlation coefficient between the L:M and EFZ of 0.40 will be statistically significant at the $p<0.05$ level with this sample size. Lesser degrees of correlation seem unlikely to be of clinical relevance.

Dietary survey. A list of foods was identified before enrollment as eaten in Masika by interviewing residents and surveying the local market. The research team has been working in surrounding villages since 2003 and is familiar with the habitual, monotonous diet of the region. Each mother was asked how often the child consumed each food during both the rainy and dry seasons and then was encouraged to volunteer other foods that the child consumed. Possible choices for the food frequency questionnaire were more than once daily, daily, 2-3 times a week, weekly, 2-3 times a month, or once a month or less. The average portion size that a child aged 3-5 y consumes of these foods, and the nutrient composition of the food was assumed to be the same as that in a previous study conducted in this district of Malawi (15). Values for average daily energy and zinc intake were calculated using the reported amount consumed on the food frequency questionnaire and previous portion size and composition data $(16,17)$.

Dual sugar absorption test. Caretakers were instructed not to give their children any food after $2200 \mathrm{~h}$ on the day before the dual sugar-absorption test and to assemble at the village research site at $0600 \mathrm{~h}$ on the day of the test. After arrival at the research site, each child voided, and the urine collected was then discarded.

To initiate the test, each child then drank a 100-mL sugar solution containing $5 \mathrm{~g}$ lactulose and $1 \mathrm{~g}$ mannitol. With a healthy gastrointestinal mucosa, mannitol is incompletely absorbed and can serve as an indicator of absorptive capacity, whereas poorly absorbed lactulose can serve as a measure of intercellular permeability.

Children remained at the village research site for at least $4 \mathrm{~h}$ after ingestion of the sugar solution, during which time all of the child's urine was collected in a sterile cup with $10 \mathrm{mg}$ merthiolate added to limit bacterial degradation of excreted sugars. When a child voided within $4 \mathrm{~h}$ of consuming the sugar solution, he/she had completed the urine collection and was dismissed. At the end of the collection period, the total urine volume was measured, and a 4-mL aliquot was transferred into a plastic cryovial. Urine specimens were flash frozen and then transported and stored at $-70^{\circ} \mathrm{C}$.

The concentrations of lactulose and mannitol in the urine specimens were analyzed as previously described (14). In brief, a $20-\mu \mathrm{L}$ aliquot of the centrifuged urine is injected onto a cation-exchange column, eluted with water, and then injected onto the HPLC analytical column. The assay was sensitive to $1 \mu \mathrm{g} / \mathrm{mL}$ for lactulose and $10 \mu \mathrm{g} / \mathrm{mL}$ for mannitol.

Dual zinc stable isotope test. ${ }^{67} \mathrm{Zn}\left(94.2 \%\right.$ enrichment) and ${ }^{70} \mathrm{Zn}(95.5 \%$ enrichment) were obtained from Trace Sciences (Toronto, Canada). Aqueous solutions of zinc chloride were prepared by Anazao Health Corporation (Tampa, FL). These solutions were tested for pyrogenicity and sterility. Isotopic distribution of the tracers was verified by thermal ionization magnetic sector mass spectrometry (Finnigan MAT 261, Bremen, Germany).

Subjects and caretakers spent the first day of the dual zinc isotope test at the Chipalonga Health Center, where they consumed a prescribed diet, and oral and i.v. zinc stable isotopes were administered. The prescribed diet was chosen to correspond to the habitual diet. Fasted subjects arrived at the health center at $0600 \mathrm{~h}$. Through the course of the day, each child was fed four times: $0700 \mathrm{~h}$ corn porridge, $1030 \mathrm{~h}$ banana, $1300 \mathrm{~h}$ corn dough with beans, and $1630 \mathrm{~h}$ corn dough with beans. Each child was offered as much of the food as he/she wanted, and only a 30-g minimum intake was required for administering the extrinsic zinc isotope. Weighed food records were kept for each child, and food samples were saved for compositional analyses. With each feeding, each child was given an exactly weighed amount of $270 \mu \mathrm{g}{ }^{67} \mathrm{Zn}$ mixed in $30 \mathrm{~g}$ food. A research team member directly verified that the child received the entire amount and that no spillage occurred. At the middle of the day, each child had a blood sample drawn to measure serum zinc and was then given an i.v. injection of an exactly weighed quantity of $500 \mu \mathrm{g}{ }^{70} \mathrm{Zn}$. At the end of this day, subjects and caretakers returned home.

Caretakers were asked to collect all stools for the next $6 \mathrm{~d}$ in a zinc-free plastic sack. Research staffs were stayed in the village with the participants throughout the duration of this study. Researchers collected fecal and/or urine samples of the children two times daily from their mother. Two complete 24-h urine collections were made between $48-72 \mathrm{~h}$ and $96-120 \mathrm{~h}$ after isotope administration. Stool samples were aggregated into three 48 -h collections, representing 0-48, 48-96, and 96-144 h after isotope administration. Samples were stored in plastic coolers in the village and transported unprocessed to the laboratories of Steve Abrams at the Children's Nutrition Research Center in Houston, TX, for analyses.

Urine and fecal specimens for total zinc and isotopic zinc ratios were analyzed as previously described $(3,6)$. Samples were first diluted with weak acid to obtain a consistent $\mathrm{Zn}$ signal intensity. ${ }^{66} \mathrm{Zn},{ }^{67} \mathrm{Zn}$, and ${ }^{70} \mathrm{Zn}$ peaks from sample solutions were analyzed by inductively coupled plasma mass spectroscopy at a high mass resolution $(\mathrm{M} /[$ Delta]M) of $\sim 4000$ to get rid of major mass interferences. Total analytical time was $2-3 \mathrm{~min}$ for each solution, and ${ }^{67} \mathrm{Zn} /{ }^{66} \mathrm{Zn}$ and ${ }^{70} \mathrm{Zn} /{ }^{66} \mathrm{Zn}$ ratios were calculated. The ratios were normalized by the analytical values of $\mathrm{Zn}$ standards with a bracket technique. Analytical precision was $\geq 0.7 \%$.

Calculations. The zinc intake of each child on the day of zinc administration was calculated using the mass of food eaten and the content of zinc in the food as measured by NP Analytic Laboratories (St. Louis, MO).

EFZ of each child was calculated using the following formula with stools collected from 48 to $144 \mathrm{~h}$ after isotope administration:

$\mathrm{EFZ}(\mathrm{mg} / \mathrm{d})=($ Total fecal zinc content of $4 \mathrm{~d}(\mathrm{mg}) \times \%$ excess fecal $\left.{ }^{70} \mathrm{Zn}\right) /\left(\%\right.$ excess urine ${ }^{70} \mathrm{Zn} \times 4 \mathrm{~d}$ of collection $)$.

Fractional absorption of zinc $(\mathrm{FAZ})=($ Oral tracer:tracee ratio/dose of oral tracer)/(i.v. tracer:tracee ratio/dose of i.v. tracer), using isotopic enrichment values in urine.

TAZ was the product of FAZ and the dietary zinc intake on the day of isotope administration. NZR $(\mathrm{mg} / \mathrm{d})=\mathrm{TAZ}(\mathrm{mg} / \mathrm{d})-\mathrm{EFZ}(\mathrm{mg} / \mathrm{d})-$ urinary and insensible zinc losses.

The oral isotope was excluded from the calculations of NZR, because the oral isotope was only administered on one of the days for which EFZ and intake were calculated and represented only $4.5 \%$ of total zinc intake for the period. Urinary and insensible losses were estimated using previously determined values (13).

Data analysis. Summary statistics were calculated for the participants as mean \pm SD for continuous parameters and $n(\%)$ for dichotomous parameters. Anthropometric $Z$ scores were calculated using ANTHRO 2005 (WHO).

The reported values for normal L:M range from 0.03 to 0.12 ; a value of $\geq 0.10$ was chosen to be abnormal, as has been done previously (14).

Least squares fit regression lines between L:M and EFZ, TAZ, NZR, and serum zinc concentration were created using SPSS 15.0 for Windows (Chicago, IL). The Pearson product-moment correlation coefficient and the statistical significance of bivariate relationship were determined using SPSS 15.0 for Windows. A linear relationship between the L:M and EFZ was assumed because mannitol absorption is a proxy measure of the functional absorptive surface area of the small bowel, and the capacity of the small bowel to absorb endogenous zinc is postulated to vary directly with the surface area. A $p$ value $<0.05$ was considered significant. 


\section{RESULTS}

The entire village population of 3-5 y olds in Masika, 91 children, was screened. Twenty-six children were selected for this study (Table 1). Of the 26 children, one set of stool and urine samples was found to have zinc isotope ratios showing low enrichment, and calculations of EFZ could not be made with these data. This subject was excluded from all analyses. None of these 26 subjects reported active diarrhea or a febrile illness, and all were playful with an unremarkable physical examination. On average, subjects passed 1.6 formed stools $/ \mathrm{d}$.

The children habitually consumed an average of $4252 \mathrm{~kJ} / \mathrm{d}$ and $5.2 \mathrm{mg} / \mathrm{d}$ of zinc (Table 2). No child reported consuming iron or multivitamin supplements. Aside from calcium and fat, these children were consuming amounts of nutrients comparable with the recommended estimated average requirements (Table 2). On the day of zinc isotope administration, the energy and zinc intakes of subjects were $5340 \pm 1320 \mathrm{~kJ}$ and $6.5 \pm 1.9 \mathrm{mg}$, respectively.

Subjects had an L:M of $0.24 \pm 0.10$ (Table 3). The median (25, 75\%tile) L:M was 0.22 (0.18, 0.28). Among the 25 subjects, 22 (88\%) had an L:M >0.10 and 18 (72\%) had an $\mathrm{L}: \mathrm{M}>0.20$.

Results from the dual zinc stable isotope tests found EFZ to be $1.68 \pm 1.06 \mathrm{mg} / \mathrm{d}$ (Table 4 ) with a median value of 1.48

Table 1. Demographic and anthropometric characteristics of 3-5-y-old Malawian children in Masika

\begin{tabular}{lc}
\hline & Enrolled $(n=25)$ \\
\hline Age (mo) & $44.9 \pm 6.8^{*}$ \\
Sex, male & $13(52 \%) \dagger$ \\
Weight $(\mathrm{kg})$ & $13.78 \pm 1.94$ \\
Heigth $(\mathrm{cm})$ & $95.4 \pm 7.4$ \\
Weight-for-height $Z$ score & $-0.37 \pm 0.86$ \\
Weight-for-age $Z$ score & $-1.07 \pm 0.82$ \\
Height-for-age $Z$ Score & $-1.41 \pm 1.37$ \\
Mean upper arm circumference $(\mathrm{cm})$ & $15.41 \pm 0.83$ \\
History of malnutrition & $10(40 \%)$ \\
Home hygiene score $(0=$ most, $25=$ & $13.5 \pm 2.6$ \\
$\quad$ least hygienic) & $19(76 \%)$ \\
No hand washing after stool & $8(32 \%)$ \\
Farm animals sleeping w/child &
\end{tabular}

* Values expressed as mean $\pm \mathrm{SD}$.

$\dagger$ Values expressed as absolute No. (\%).

Table 2. Habitual dietary intake of the Malawian children aged 3-5 y studied

\begin{tabular}{lcc}
\hline \multicolumn{1}{c}{ Nutrient } & Mean intake & EAR \\
\hline Energy $(\mathrm{kJ} / \mathrm{d})$ & 4272 & 4284 \\
Protein $(\mathrm{g} / \mathrm{d})$ & 24 & 19 \\
Fat $(\mathrm{g} / \mathrm{d})$ & 11.7 & 30 \\
Vitamin A $(\mu \mathrm{g} / \mathrm{d})$ & 545 & 400 \\
Folate $(\mu \mathrm{g} / \mathrm{d})$ & 234.2 & 200 \\
Calcium $(\mathrm{mg} / \mathrm{d})$ & 363.1 & 500 \\
Phosphorus $(\mathrm{mg} / \mathrm{d})$ & 640.7 & 500 \\
Iron $(\mathrm{mg} / \mathrm{d})$ & 7.9 & 7 \\
Zinc $(\mathrm{mg} / \mathrm{d})$ & 5.2 & 3 \\
Copper $(\mathrm{mg} / \mathrm{d})$ & 1.1 & 0.44 \\
Phytate $(\mathrm{mg} / \mathrm{d})$ & 1019.1 & \\
Phytate:Zn molar ratio & 22 &
\end{tabular}

Values determined using a quantitative food frequency questionnaire. EAR, estimated average requirement. $\mathrm{mg} / \mathrm{d}$. FAZ had a mean value of $43 \%$ and a median value of $31 \%$, with the 25 th-75th percentile range of $25-37 \%$. EFZ and TAZ were not found to be correlated $(r=-0.12, p=$ 0.54). Among the 25 subjects, 7 (28\%) had a serum zinc $<0.66 \mathrm{mg} / \mathrm{L}$, which the testing laboratory identified as below the normal range (18). Among these seven children, EFZ was

Table 3. Gut function and integrity—site-specific sugar absorption test results

\begin{tabular}{lc}
\hline & Subjects $(n=25)$ \\
\hline Lactulose, \% absorbed & $0.37 \pm 0.16$ \\
Mannitol, \% absorbed & $8.5 \pm 3.0$ \\
Lactulose:mannitol ratio & $0.24 \pm 0.10$ \\
\hline
\end{tabular}

Values expressed as mean $\pm \mathrm{SD}$.

Table 4. Zinc homeostasis indicators-dual zinc stable isotope test results

\begin{tabular}{lc}
\hline & Subjects $(n=25)$ \\
\hline Endogenous fecal zinc $(\mathrm{mg} / \mathrm{d})$ & $1.68 \pm 1.06$ \\
Total absorbed Zn, $(\mathrm{mg})$ & $2.58 \pm 1.08$ \\
Fractional absorbed zinc $(\%)$ & $43 \pm 19$ \\
Net retained zinc $(\mathrm{mg} / \mathrm{d})$ & $0.67 \pm 1.59$ \\
Serum zinc $(\mathrm{mg} / \mathrm{L})$ & $0.75 \pm 0.14$ \\
\hline
\end{tabular}

Values expressed as mean $\pm \mathrm{SD}$.
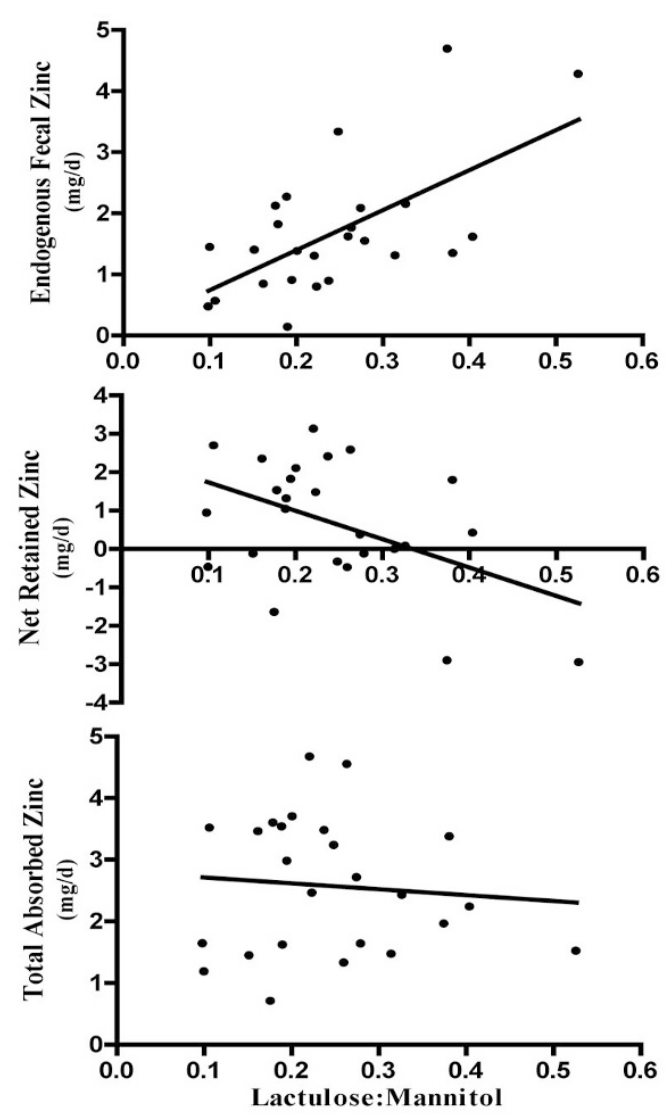

Figure 1. Relationship between L:M and endogenous fecal zinc, net retained zinc and total absorbed zinc (the primary determinants of zinc homeostasis). The lines shown are the best fit linear models generated by using a least squares line fitting technique. The Pearson's correlation coefficient, $r$ value, for L:M with EFZ is $0.62(p<0.001)$ and for L:M with NZR is $-0.47(p<$ $0.02)$. 
$1.61 \pm 0.71 \mathrm{mg} / \mathrm{d}$. No differences in any TAZ or NZR were found between those subjects with low serum zinc and those with normal levels.

The L:M positively correlated with EFZ $\left(r^{2}=0.39, p<\right.$ $0.001)$ and negatively correlated with NZR $\left(r^{2}=-0.22, p=\right.$ 0.02 ) but did not correlate with TAZ (Fig. 1). Fraction of administered mannitol recovered in the urine similarly correlated with $\mathrm{EFZ}\left(r^{2}=-0.21, p=0.02\right)$ and NZR $\left(r^{2}=0.25\right.$, $p=0.01)$. Fraction of lactulose recovered in the urine showed no significant correlation with EFZ $\left(r^{2}=0.01, p=0.60\right)$ or NZR $\left(r^{2}=0.01, p=0.70\right)$. No significant correlations with serum zinc and the L:M, serum zinc and any of the fractional sugar absorptions, or serum zinc and any of the other zinc homeostatic parameters were found.

\section{DISCUSSION}

This study found that among rural sub-Saharan African children, among whom tropical enteropathy was common and risk for zinc deficiency was high, the L:M was directly correlated with EFZ and negatively correlated with NZR. Mannitol absorption, rather than lactulose absorption, was associated with zinc homeostasis. Among the population studied, zinc homeostasis was perturbed in that EFZ was not reduced in children who were zinc deficient.

The estimates for FAZ in several study children were higher than might be expected, $>40 \%$, given that the diet contained a large quantity of phytate. This might well be the consequence of the method of isotope administration: oral isotope mixed with a small amount of food. Particularly with the afternoon meal of banana, the added aqueous $\mathrm{ZnCl}_{2}$ isotope might well have been absorbed more completely than zinc in a food matrix. Overestimates of FAZ result in overestimation of TAZ. This limitation prevents us from drawing any conclusions about the association of TAZ with either EFZ or the L:M in this dataset. This methodological concern does not affect estimates of EFZ and does not affect the primary findings of this study.

We chose enrollment criteria for participants presumed to include a range of L:Ms and then looked for an association between the L:M and indicators of zinc homeostasis, rather than choosing two groups of subjects, those with and without abnormal L:Ms, and comparing the mean indicators of zinc homeostasis between the two groups. This choice was made because of two practical constraints. The first was that this study site was far removed from the laboratory facilities, so that all subjects would have their testing for both enteropathy and zinc homeostasis before any test results were known. The second constraint was that study participation required a tremendous level of commitment and dedication for an entire week on the part of the mothers and thus all children in the village could not be studied.

This study was limited in that it examined a population of young children in rural, agrarian Malawi consuming a plantbased, high phytate diet. Caution should be exercised in extending our findings to populations in which tropical enteropathy and zinc deficiency are less common, such as urban populations or those with increased consumption of animal source foods or breast milk. In addition, adult populations, which have understandably higher EFZs and total zinc intakes, may have dissimilar zinc homeostatic indicators than younger children. The demographic group chosen for our study does represent the individuals that most commonly exhibit tropical enteropathy as well as zinc deficiency. Because fecal markers were not used in this study, the amount of tracer excreted into the gut during the collection period may be underestimated. This error is probably small because of the rapid gut transit time in these children, and such an error would have caused us to underestimate EFZ. The population studied is at high risk for chronic, asymptomatic parasitic infestation of the gastrointestinal tract. No testing of the children's stools was undertaken for the presence of parasites or bacteria, so what role subclinical infection played is unknown.

The L:M $>0.20$ in our study population indicates abnormalities in small intestinal function, and permeability were common in our population, and these findings are similar to L:Ms found in other studies of Malawian and Gambian children of similar ages $(9,14)$. This study is the first in which the dual sugar absorption and dual zinc stable isotope tests were used together. A report from Brazilian children found no correlation between serum zinc and the L:M (18), which is similar to what we found. It is recognized that serum zinc is not an accurate biomarker of zinc status in individuals, although it is the most widely used biochemical indicator (19).

Reducing EFZ is believed to be a homeostatic control mechanism to conserve zinc $(2,20)$. The EFZ of $1.68 \pm 1.06$ $\mathrm{mg} / \mathrm{d}$ from young Malawian children of this study is greater and has more variability than that seen in studies from more developed settings, where EFZ was found to be $0.99 \pm 0.40$ $\mathrm{mg} / \mathrm{d}$ in US children aged $1-4$ y (3), $1.08 \pm 0.62 \mathrm{mg} / \mathrm{d}$ in US girls aged $9-14 \mathrm{y}(6)$, and $0.66 \pm 0.23 \mathrm{mg} / \mathrm{d}$ in Chinese children aged 1.5-2 y (5). Studies in school-age children from the developing world have found EFZ to be $1.53 \mathrm{mg} / \mathrm{d}$ in Malawi (13) and $1.56 \mathrm{mg} / \mathrm{d}$ in Guatemala (4). Some researchers normalize EFZ to body weight. Although a typical EFZ normalized to body weight in populations in North America, China, and Central America is $0.06 \mathrm{mg} / \mathrm{kg} / \mathrm{d}$ (4), our mean EFZ was $0.12 \mathrm{mg} / \mathrm{kg} / \mathrm{d}$. EFZ was $\sim 0.7 \mathrm{mg} / \mathrm{d}$ greater than estimates from developed world populations. This is an amount equal to the NZR in our population. If a similar EFZ was seen with more modest zinc intake, perhaps during times of food shortage or febrile illness, EFZ might well exacerbate zinc deficiency. The relatively large values for EFZ seen in this study is indicative that EFZ may well be perturbing zinc balance rather than preserving it.

Zinc absorption may have been limited by reduced absorptive capacity of the distal small bowel in these Malawian children. Our data indicate that this was a particular problem for secreted endogenous zinc. Evidence from compartmental modeling studies in healthy volunteers and children with cystic fibrosis suggests that secreted endogenous zinc is absorbed at sites in the gastrointestinal tract that are distal to the proximal jejunum, whereas dietary zinc is primarily absorbed in the duodenum and proximal jejunum (21).

Assessment of gut absorptive capacity and permeability using the L:M test in conjunction with high-dose zinc supple- 
mentation after diarrheal episodes indicates that zinc supplementation restores normal permeability, as measured by urinary lactulose recovery, but does not affect absorptive capacity, as measured by urinary mannitol recovery (22). In this study, the relationship between EFZ and the L:M is based on abnormal absorptive capacity, leading to speculation that enteropathy is further compromising zinc status by inadequate reabsorption of endogenous zinc.

These data provide no insight into the temporal relationship between presumed tropical enteropathy and perturbed zinc homeostasis. Tropical enteropathy is the result of an environmental insult; it has been noted in infants to first occur between 2 and 4 mo of age, increase in prevalence during the first 18 mo of life, and persist into adulthood (9). Tropical enteropathy occurs in expatriate individuals living in the developing world-individuals who are likely to have an adequate diet and a normal nutritional status (11). Tropical enteropathy resolves for individuals of all ethnicities residing in the hygienic settings. The prevalence of zinc deficiency is difficult to assess given that there are not reliable biomarkers of zinc status. Indirect evidence exists that zinc deficiency occurs in young, exclusively breast-fed children, increases in prevalence in the first $2 \mathrm{y}$ of life, and persists into adulthood, similar to tropical enteropathy.

The pathology of zinc deficiency includes changes in enterocyte microstructure without gross morphologic aberrancies (23); an abundance of lysosome-like bodies is reported as is the flattening of villi and significantly decreased crypt cell production rates. These observations suggest that tropical enteropathy and zinc deficiency exacerbate one another.

The observation that EFZ and L:M are directly correlated suggests that interventions to ameliorate enteropathy and prevent zinc deficiency will be interrelated. Although great attention has been placed on reducing mineral deficiencies through supplements and dietary interventions, the problem of zinc deficiency might not be resolved without reducing the severity and prevalence of tropical enteropathy. More research may well be required on enteropathy before effective interventions to end zinc deficiency are realized.

\section{REFERENCES}

1. Black RE, Allen LH, Bhutta ZA, Caulfield LE, de Onis M, Ezzati M, Mathers C, Rivera J 2008 Maternal and child undernutrition: global and regional exposures and health consequences. Lancet 371:243-260
2. Sian L, Mingyan X, Miller LV, Tong L, Krebs NF, Hambidge KM 1996 Zinc absorption and intestinal losses of endogenous zinc in young Chinese women with marginal zinc intakes. Am J Clin Nutr 63:348-353

3. Griffin IJ, Lynch MF, Hawthorne KM, Chen Z, Hamzo M, Abrams SA 2007 Zinc homeostasis in 1-4 year olds consuming diets typical of US children. Br J Nutr 98:358-363

4. Hambidge KM, Mazariegos M, Solomons NW, Westcott JE, Lei S, Raboy V, Grunwald G, Miller LV, Sheng X, Krebs NF 2007 Intestinal excretion of endogenous zinc in Guatemalan school children 137:1747-1749

5. Sheng XY, Hambidge KM, Zhu XX, Ni JX, Bailey KB, Gibson RS, Krebs NF 2006 Major variables of zinc homeostasis in Chinese toddlers. Am J Clin Nutr 84:389394

6. Griffin IJ, Hicks PD, Liang LK, Abrams SA 2004 Metabolic adaptations to low zinc intakes in premenarcheal girls. Am J Clin Nutr 80:385-390

7. Campbell DI, Murch SH, Elia M, Sullivan PB, Sanyang MS, Jobareth B, Lunn PG 2003 Chronic T cell-mediated enteropathy in rural west African children: relationship with nutritional status and small bowel function. Pediatr Res 54:306-311

8. Kelly P, Menzies I, Crane R, Zulu I, Nickols C, Feakins R, Mwansa J, Mudenda V, Katubulushi M, Greenwald S, Farthing M 2004 Responses of small intestinal architecture and function over time to environmental factors in a tropical population. Am J Trop Med Hyg 70:412-419

9. Lunn PG, Northrop-Clewes CA, Downes RM 1991 Intestinal permeability, mucosa injury and growth faltering in Gambian infants. Lancet 338:907-910

10. Brown KH, Khatun M, Ahmed G 1981 Relationship of the xylose absorption status of children in Bangladesh to their absorption of macronutrients from local diets. Am J Clin Nutr 34:1540-1547

11. Menzies IS, Zuckerman MJ, Nukajam WS, Somasundaram S, Murphy B, Jenkins A, Crane R, Gregory G 1999 Geography of intestinal permeability and absorption. Gut 44:483-489

12. Shulman RJ, Eakin MN, Czyzewski DI, Jarrett M, Ou CN 2008 Increased gastrointestinal permeability and gut inflammation in children with functional abdominal pain and irritable bowel syndrome. J Pediatr 153:646-650

13. Manary MJ, Hotz C, Krebs NF, Gibson RS, Westcott JE, Arnold T, Broadhead RL, Hambidge KM 2000 Dietary phytate reduction improves zinc absorption in Malawian children recovering from tuberculosis but not in well children. J Nutr 130:29592964

14. Galpin L, Manary MJ, Fleming K, Ou CN, Ashorn P, Shulman RJ 2005 Effect of Lactobacillus GG on intestinal integrity in Malawian children at risk of tropical enteropathy. Am J Clin Nutr 82:1040-1045

15. Sullivan J, Ndekha M, Maker D, Hotz C, Manary MJ 2006 The quality of the die in Malawian children with kwashiorkor and marasmus. Matern Child Nutr 2:114 122

16. Hotz C, Gibson RS 2001 Complementary feeding practices and dietary intakes from complementary foods amongst weanlings in rural Malawi. Eur J Clin Nutr 55:841849

17. Yeudall F, Gibson RS, Cullinan TR, Mtimuni B 2005 Efficacy of a community-based dietary intervention to enhance micronutrient adequacy of high-phytate maize-based diets of rural Malawian children. Public Health Nutr 8:826-836

18. Hambidge M 2003 Human zinc homeostasis: good but not perfect. J Nutr 133:1438S-1442S

19. Chen P, Soares AM, Lima AA, Gamble MV, Schorling JB, Conway M, Barrett LJ, Blaner WS, Guerrant RL 2003 Association of vitamin A and zinc status with altered intestinal permeability: analyses of cohort data from northeastern Brazil. J Health Popul Nutr 21:309-315

20. Hotz C, Peerson JM, Brown KH 2003 Suggested lower cutoffs of serum zinc concentrations for assessing zinc status: reanalysis of the second National Health and Nutrition Examination Survey data (1976-1980). Am J Clin Nutr 78:756-764

21. Krebs NE, Hambidge KM 2001 Zinc metabolism and homeostasis: the application of tracer techniques to human zinc physiology. Biometals 14:397-412

22. Roy SK, Behrens RH, Haider R, Akramuzzaman SM, Mahalanabis D, Wahed MA, Tomkins AM 1992 Impact of zinc supplementation on intestinal permeability in Bangladeshi children with acute diarrhoea and persistent diarrhoea syndrome. J Pediatr Gastroenterol Nutr 15:289-296

23. Koo SI, Turk DE 1977 Effect of zinc deficiency on the ultrastructure of the pancreatic acinar cell and intestinal epithelium in the rat. J Nutr 107:896-908 